\title{
La educación jurídica en Brasil: una lectura crítica de las directrices curriculares nacionales brasileñas para el derecho y sus formas de recontextualización a partir de las teorías de Basil Bernstein
}

\section{Legal education in Brazil: a critical reading of the Brazilian national curricular guidelines for the law and their forms of re-contextualization from the theories of Basil Bernstein}

Renato Duro Dias ${ }^{1}$

\begin{abstract}
Resumen: el Proyecto Pedagógico de organización de una carrera de Derecho se aplica en una universidad del sur de Brasil para mejorar la calidad de la educación impartida, en el sentido de incorporar la formación práctica y articular un currículum integrado entre las distintas asignaturas; siendo el objetivo final la formación de un licenciado crítico, reflexivo y agente de transformación social. La ideología que está presente es la que el autor denomina "educación emancipadora", que se basa en una visión transdisciplinar del Derecho y las Ciencias Humanas y Sociales y que pretende formar un licenciado consciente de la diversidad cultural y humana existente en la sociedad, donde él mismo debe ser un elemento participativo.
\end{abstract}

Palabras clave: educación emancipadora, currículum integrado, ciudadanía activa.

\begin{abstract}
Brazil to improve the quality of education provided in in order to incorporate practical training and articulate an integrated curriculum between different subjects. The ultimate goal was the formation of a critical, reflective and agent of social transformation graduate. The idology present is what the author calls "emancipatory education" which is based on a transdisciplinary vision of law and human and social sciences. This ideology aims to educate a conscious graduate of the cultural and human diversity in society, where he/she should be a participatory element.
\end{abstract}

Key words: emancipatory education, integrated curriculum, participatory citizenship.

\section{Introducción}

En el cotidiano universitario, en los salones de clase y en los pasillos, en las reuniones de Consejo de Facultad y en los desenfadados encuentros de café, la carrera de Derecho de una Facultad de Derecho del sur del Brasil (docentes, discentes y técnicoadministrativos) sistemáticamente vienen reflexionando sobre la temática central de este artículo: el

\footnotetext{
${ }^{1}$ Profesor Asistente de la Facultad de Derecho, Universidade Federal de Río Grande/FURG, Río Grande/ RS/Brasil, Doctorando en Educación/ FaE/UFPel. Correo electrónico: renatodurodias@ gmail.com.
} 
currículo de la Carrera, la educación emancipadora y la integración, incluso con delineamientos para una nueva propuesta de organización curricular.

En este contexto, como autor de este artículo, procuro reflexionar sobre las teorías curriculares $^{2}$ y bien así sus articulaciones con la enseñanza jurídica de modo de comprender cómo aquellas teorías pueden subsidiar una propuesta de integración curricular que viabilice una educación emancipadora en la perspectiva de la enseñanza jurídica.

Además, la importancia del tema propuesto se vislumbra como un medio eficaz que posibilite la formación de un Licenciado en Derecho crítico, reflexivo y agente de transformación social, ya que operacionalizar el entrelazamiento de la teoría y la práctica (integración curricular del eje de formación práctica con los ejes, fundamental y profesional) constituye un reto puesto para des-pensar ${ }^{3}$ el Derecho $^{4}$ y la enseñanza jurídica.

Pienso que este artículo permitirá, por lo tanto, una comprensión más amplia y crítica de los procesos de construcción e implementación curricular en la esfera local (Proyecto pedagógico de organización de la carrera de Derecho), y la relevancia para el campo del Derecho $^{5}$ (saber jurídico, esencialmente, la enseñanza jurídica) y avanza en el sentido de la pluralidad del conocimiento, oponiéndose a su fragmentación, constituyéndose, así, como mecanismo de garantía de la diversidad expresa en la individualidad y en lo colectivo por la mirada da educación transformadora, dialéctica y reflexiva (en Adorno y Horkheimer ${ }^{6}$, una educación de esclarecimiento).

\section{La enseñanza jurídica}

Numerosos estudios -Rodrigues ${ }^{7}$; Leite $^{8}$; Santos y Morais ${ }^{9}$; Nalini y Carlini ${ }^{10}$; Bittar $^{11}$;Fragale Filho ${ }^{12}$ y Henning ${ }^{13}$ - se han inclinado sobre la problemática de la

\footnotetext{
${ }^{2}$ Ver: SILVA, Tomaz Tadeu da y MOREIRA, Antonio Flávio (Orgs.). Territórios contestados: o currículo e os novos mapas políticos e culturais. $4^{\mathrm{a}}$ ed. Petrópolis, Río do Janeiro, 2001; SILVA, Tomaz Tadeu da. $O$ currículo como fetiche - a poética e a política do texto curricular. Belo Horizonte: Autêntica, 2003; SILVA, Tomaz Tadeu da. Documentos de identidade. $2^{\mathrm{a}}$ ed. Belo Horizonte: Autêntica, 2005; LOPES, Alice Casemiro y MACEDO, Elizabeth (Orgs.). Disciplinas e integração curricular: história e políticas. Río de Janeiro: DP\&A, 2002; LOPES, Alice Ribeiro Casemiro; MACEDO, Elizabeth Fernandes de y ALVES, Maria Palmira Carlos (Orgs.) Cultura e política de currículo. Araraquara, SP: Junqueira \& Marin Editores, 2006.

3 "Des-pensar es una tarea epistemológica compleja porque implica una des-construcción total, pero no nihilista, es una reconstrucción discontinua, pero no arbitraria". De acuerdo con Santos (SANTOS, Boaventura de Souza. A critica da razão indolente: contra o desperdício da experiência. Para um novo senso comum. A ciência, o direito e a política na transição paradigmática. V. 1. Sao Paulo: Cortez Editora, 2000. P. 186).

4 "Es legítimo pensar que la crisis del paradigma de la ciencia moderna acarrea consigo la crisis del paradigma del derecho moderno" (SANTOS, Boaventura de Souza. Ibíd. P. 164).

${ }^{5}$ FERRAZ Jr., Tércio Sampaio. A ciência do direito. $2^{\mathrm{a}}$ ed. Sao Paulo: Atlas, 1980.

${ }^{6}$ ADORNO, Theodor W. Emancipação e educação. Sao Paulo: Paz e Terra, 2010; y ADORNO, Theodor W. y HORKHEIMER, Max. Dialética do esclarecimento. Río de Janeiro: Jorge Zahar Editor, 1969.

${ }^{7}$ RODRIGUES, Horácio Wanderlei. Pensando o ensino do direito no século XXI: diretrizes curriculares, projeto pedagógico e outras questões pertinentes. Florianópolis: Boiteux, 2005.

${ }^{8}$ LEITE, Maria Cecilia Lorea. Decisões pedagógicas e inovações no ensino jurídico. v. I. Tesis de Doctorado. Programa de Postítulo en Educación. Porto Alegre: UFRGS, 2003; LEITE, Maria Cecilia Lorea y VANDÚNEM, José Octávio S. “Avaliação do curso de direito e inovações: desafios da pedagogia jurídica”. En:
} 
enseñanza jurídica y sus interfaces con las innovaciones pedagógicas y las Directrices Curriculares Nacionales propugnadas por el Consejo Nacional de Educación. En razón de la importancia del tema, se intentará, en este escrito, problematizar el Proyecto Pedagógico de organización de una Carrera de Derecho, específicamente el eje de formación práctica y su integración ${ }^{14}$ curricular con los demás ejes, en la perspectiva de buscar una educación emancipadora en favor de la formación de un Licenciado: crítico, reflexivo y agente de transformación social.

\section{La carrera de Derecho analizada}

La carrera de Derecho en análisis está situada en la región sur del Brasil y fue creada en la misma fecha de fundación de la Facultad de Derecho, vale decir, el 05 de agosto de 1959, autorizada a funcionar por el Gobierno Nacional, el 08 de enero de 1960, por el Decreto $\mathrm{n}^{\circ} 47.738$, publicado el 02 de febrero de 1960 , y con reconocimiento desde la fecha de 14 de junio de 1965, por el Decreto $n^{\circ} 56.461$, publicado en el Boletín oficial del Estado, el 06 de julio del mismo año. La institución mantenedora a la época, denominada Facultad de Derecho "Clóvis Bevilácqua" por su instituidora, Mitra Diocesana, era vinculada a una universidad privada $\mathrm{y}$, a partir de 1972, fue incorporada a una fundación pública. La última fundada el 20 de agosto de 1969.

Según Valle ${ }^{15}$ :

La primera matriz curricular de la entonces Facultad de Derecho "Clóvis Bevilácqua" no contemplaba disciplinas que indicasen una definición vocacional, como actualmente ocurre. Acompañando el contexto educacional de la época, la facultad formaba Licenciados en Ciencias Jurídicas y Sociales, bajo régimen anual, con un cuerpo de disciplinas distribuidas en cinco series.

GHIGGI, Gomercindo y VAN-DÚNEM, José Octávio S. (Orgs.). Diálogos educativos entre Brasil e Angola. Pelotas, RS: Editora e Gráfica Universitária, UFPel, 2007.

${ }^{9}$ SANTOS, André Leonardo Copetti y MORAIS, José Luis Bolzan de. O ensino jurídico e a formação do bacharel em Direito - Diretrizes político-pedagógicas do curso de direito da UNISINOS. Porto Alegre: Livraria do Advogado, 2007.

${ }^{10}$ NALINI, José Renato y CARLINI, Angélica (Coord.) Direitos humanos e formação jurídica. Forense. Río de Janeiro, 2010.

${ }^{11}$ BITTAR, Eduardo C. B. "O ensino jurídico na pós-modernidade". En: Anuário ABEDI (Associação Brasileira de Ensino do Direito). 2005, año 3, núm. 3.

${ }^{12}$ FRAGALE FILHO, Roberto. "Diretrizes curriculares". En: Anuário ABEDI (Associação Brasileira de Ensino do Direito). 2004, año 2, núm. 2.

${ }^{13}$ HENNING, Ana Clara Correa. "Conexões entre cultura popular e cultura acadêmica: recontextualização curricular na prática de pesquisa jurídica do curso de direito da Anhanguera Educacional / Faculdade Atlântico Sul em Pelotas". Disertación de Maestría, Programa de Postítulo en Educación. Pelotas: Facultad de Educación. RS, UFPel, 2008.

${ }^{14}$ En este aspecto, utilizo el término integración en los sentidos señalados: en el Proyecto Pedagógico de Organización de la Carrera de Derecho; en las Directrices Curriculares Nacionales para las Carreras de Derecho (Decreto n. 09/2004 CNE/CES) y en las teorías curriculares integradoras.

${ }^{15}$ VALLE, Leila Mara Barbosa Costa. "O curso de direito na FURG”. En: Revista Júris. 2005, núm. 11, p. 35. 
En su trayecto histórico, además de los estudios de formación básica, la carrera de Derecho analizada introdujo en su currículo -antes, y después de asimilar las directrices vocacionales de la Universidad- las disciplinas de Derecho Internacional Público y Privado, Derecho Comercial Marítimo, Derecho del Mar, Derecho Ambiental y Legislación Portuaria y Pesquera.

En esta perspectiva, la carrera de Derecho en análisis venía adecuando el desarrollo de los contenidos programáticos de las disciplinas a las nuevas directrices y a los preceptos constitucionales de derechos sociales, individuales y colectivos ${ }^{16}$, con enfoque especial a los derechos y garantías fundamentales, entre ellos el de un medio ambiente ecológicamente equilibrado, razón por la que estos dos pilares pasaron a ser el foco de la estructuración curricular.

Por decirlo así, el proyecto pedagógico es determinante a la hora de determinar la dirección en la formación y perfil del egreso. Vale decir, un profesional que, por encima de todo, reconozca en la ciudadanía ${ }^{17}$ y en la pluralidad la contribución para una sociedad democrática y emancipada. De acuerdo con lo explicitado en el proyecto pedagógico de la Carrera de Derecho ${ }^{18}$ estudiada:

El objetivo general de la Carrera es la formación de ciudadanos y operadores conscientes de los valores implícitos en las esferas del Derecho Público y Privado, y bien así de los límites e interacciones entre el espacio estatal y el no estatal; que se perciban partícipes del proceso de construcción del Derecho y de la sociedad y que, sin perjuicio de sólida formación general, pautados en valores éticos, sociales y humanísticos estén capacitados a la actuación político-jurídica, en especial en el ámbito regional. Y, todavía, atendiendo a su vocación específica, contribuir para que sean ciudadanos y profesionales capaces de defender con celo especial los Derechos Fundamentales y el Medio Ambiente.

Es importante poner de relieve que estas decisiones locales, en especial sobre la estructura curricular, fueron viables, pues en la esfera nacional el Estado ${ }^{19}$ trató de dar soporte a la creación de directivas nacionales. Según Rodrigues ${ }^{20}$ "el modelo de currículo mínimo para las Carreras de Derecho surge (embrionariamente) en 1962, con una decisión del, entonces, Consejo Nacional de Educación".

\footnotetext{
${ }^{16}$ Sobre el tema, ver ALEXY, Robert. Teoria dos direitos fundamentais. Sao Paulo: Malheiros, 2008.

${ }^{17}$ MARSHALL, T. H. Cidadania, classe social e status. Río de Janeiro: Zahar Editores, 1967.

18 BRASIL. Decreto Ministerial $\mathrm{n}^{\circ} 1886$. Fixa as diretrizes curriculares e o conteúdo mínimo do curso jurídico, 30 de diciembre de $1994 . \quad$ Disponible en web: http://www.oab.org.br/arquivos/pdf/LegislacaoOab/LegislacaosobreEnsinoJuridico.pdf [consultado el $12 \mathrm{de}$ septiembre de 2010]

${ }^{19}$ DAHL, Robert. Sobre a democracia. Brasília: Editora UnB, 2001.

${ }^{20}$ RODRIGUES, Horácio Wanderlei. Pensando o Ensino do Direito no Século XXI. Florianópolis: Fundação Boiteux, 2005. P. 63.
} 
LA EDUCACIÓN JURÍDICA EN BRASIL: UNA LECTURA CRÍTICA DE LAS DIRECTRICES CURRICULARES NACIONALES BRASILEÑAS PARA EL DERECHO Y SUS FORMAS DE RECONTEXTUALIZACIÓN A PARTIR DE LAS TEORÍAS DE BASIL BERNSTEIN

\section{Las directrices curriculares nacionales}

Conforme afirma Rodrigues (2005, p. 61) ${ }^{21}$, “en el período comprendido entre 1827 a 1961 las Facultades de Derecho tenían el mismo currículo pleno predeterminado (fijo y rígido), compuesto por nueve cátedras y con duración de cinco años”. Con la declaración de independencia de la República hubo la retirada de algunas de esas disciplinas, como por ejemplo, Derecho Eclesiástico y pasan a surgir las disciplinas de Filosofía del Derecho e Historia del Derecho ${ }^{22}$.

Se nota que esas alteraciones reflejan anhelos desde la fundación de la primera carrera de Derecho, en "São Paulo" en 1827, ya que de acuerdo con Santos y Morais "23 “con la fundación de la academia de Derecho de "São Paulo", las Carreras de Derecho, tuvieron papel relevante en la formación de actores jurídicos de los lugares de ejercicio del poder".

La implementación efectiva de un nuevo modelo de currículo mínimo, en la década de 1990, posibilitó, de manera parcial, la autonomía de las Universidades y Facultades para reglamentar sus estructuras curriculares. Sin embargo, lo que en la práctica ha ocurrido, ha sido la permanencia de estructuras rígidas, ya que en la mayoría de las instituciones se flexibilizó poco en términos curriculares. A la par de esta rigidez, se ha mantenido la enseñanza fragmentada y (positivismo ${ }^{24}$ ) conservador.

En la década de 1990 surge el Decreto Ministerial n. 1.886 de 30 de diciembre de 1994 que refuerza y reglamenta la idea de currículo mínimo para las carreras de Derecho. Esa formación desconectada de la realidad, imperada por el tecnicismo, posibilitó que por Decreto se regulase las carreras existentes, y suministrara criterios para las instituciones que fueran a crear la oferta académica para la carrera de Derecho, ya que fue en ese período que comenzó la expansión de la matrícula en Derecho, principalmente, en las instituciones privadas $^{25}$.

Sin embargo, fue el Decreto n. 09, de 27 de septiembre de $2004^{26}$, del Consejo Nacional de Educación, que, en el ámbito de sus atribuciones, deroga el Decreto Ministerial n. 1.886 de 30 de diciembre de $1994^{27}$, y fijó las actuales directrices curriculares y el nuevo contenido mínimo para las carreras de Derecho, iniciando amplia y profundas modificaciones en ellas.

\footnotetext{
${ }^{21}$ RODRIGUES, Horácio Wanderlei. Ibíd. P. 61.

${ }^{22}$ Ibíd. P. 62.

${ }^{23}$ SANTOS, André Leonardo Copetti e MORAIS, José Luis Bolzan de. O ensino jurídico e a formação do bacharel em Direito - Diretrizes político-pedagógicas do curso de direito da UNISINOS. Porto Alegre: Livraria do Advogado, 2007. P. 60.

${ }^{24}$ Ver: "Para des-pensar o Direito" In: A Crítica da Razão Indolente [...]. Ibíd.

${ }^{25}$ RODRIGUES, Horácio Wanderlei. Ibíd. P. 133.

${ }^{26}$ Decreto del Consejo Nacional de Educación - Cámara de Educación Superior $\mathrm{n}^{\circ}$ 09. Instituye las directrices curriculares nacionales de la Carrera de Graduación en Derecho y da otras providencias. 27 de septiembre de 2004. Disponible en web: http://portal.mec.gov.br/cne/arquivos/pdf/rces09_04.pdf [consultado en abril de 2012].

27 BRASIL. Decreto Ministerial n 1886. Ibíd.
} 
La carrera de Derecho que ahora se investiga, a través de la Deliberación COEPE $\mathrm{n}^{\circ}$ 051/95, fue una de las primeras a implementar las innovaciones del Decreto n. 1.886/94, extendiendo su duración a seis años, implementando las "actividades complementares" y adoptando el "trabajo de conclusión de carrera". Las Directrices Curriculares Nacionales, a las que se adaptó la carrera de Derecho, por fuerza del Decreto del CNE/CES N. ${ }^{\circ} 09$ de 2004 y que pasó a regular la materia, incluyeron innovaciones y nuevas regulaciones de elementos definidos en la norma anterior ${ }^{28}$, poniéndose de relieve, en suma, el aumento del total de horas y del tiempo previsto para completar la carrera; manutención de la presentación y defensa de trabajo de término de carrera; abarcando mayor número de actividades de prácticas; implementando las horas para actividades complementares; así como también el deber de explicitación del proyecto pedagógico. Estas nuevas determinaciones, por otro lado, vinieron, al encuentro del interés de la administración de la carrera, de los docentes y de los discentes en un época en que se promovía la necesidad de la revisión y reformulación curricular, consolidando estudios y evaluaciones que continuamente eran mantenidas por la entonces "Comisión de Carrera", que correspondía a la antigua estructura Universitaria, ahora denominada "Coordinación de Carrera".

Siguiendo las Directrices Curriculares Nacionales las carreras de Derecho, en general, se organizaron en torno a tres ejes ${ }^{29}$. A saber: el eje de formación general (propedéutica), el eje de formación profesional (técnico-dogmático) y el eje de formación práctica (actuante).

A este último ha quedado la tarea de integrarse a los demás, realizando la llamada “integración curricular", explicitadas tanto en la normativa nacional (art. $2^{\circ}$, inciso V y el art. 5, inciso III del Decreto n. 09/2004 CNE/CES) como en el Proyecto Pedagógico de la carrera de Derecho (ítem 4.3), como se puede ver en los artículos transcritos abajo:

Art. 2. ${ }^{\circ}[\ldots] \S 1 .^{\circ}$ El Proyecto Pedagógico de Carrera, además de clara concepción de Carrera de Derecho, con las peculiaridades, su currículo pleno y su operacionalización, abarcará, sin perjuicio de otros, los siguientes elementos estructurales: [...] IV - formas de realización de interdisciplinaridad; V - modos de integración entre teoría y práctica;

Art. 5. ${ }^{\circ}[\ldots]$ III - Eje de Formación Práctica objetiva integración entre práctica y los contenidos teóricos desarrollados en los demás Ejes, especialmente en las actividades relacionadas con las Prácticas Curriculares Supervisadas, Trabajo de Carrera y Actividades Complementares.

\subsection{Eje de Formación Práctica}

\footnotetext{
${ }^{28}$ BRASIL, Decreto Ministerial n. 1886/94. Ibíd.

29 Art. $5^{\circ}$ La Carrera de graduación en Derecho deberá contemplar, en su Proyecto Pedagógico y en su Organización Curricular, contenidos y actividades que atiendan a los siguientes ejes interconectados de formación:

I - Eje de Formación Fundamental, tiene por objetivo integrar el estudiante en el campo, estableciendo las relaciones del Derecho con otras áreas del saber, abarcando entre otros, estudios que involucren contenidos esenciales sobre Antropología, Ciencia Política, Economía, Ética, Filosofía, Historia, Psicología y Sociología. II - Eje de Formación Profesional, abarcando, además del enfoque dogmático, el conocimiento y la aplicación, [...], entre otros que condigan con el proyecto pedagógico, contenidos esenciales sobre Derecho Constitucional, Derecho Administrativo, Derecho Tributario, Derecho Penal, Derecho Civil, Derecho Empresarial, Derecho del Trabajo, Derecho Internacional y Derecho Procesal; y III - Eje de Formación Práctica, objetiva la integración entre la práctica y los contenidos teóricos desarrollados en los demás Ejes, especialmente en las actividades relacionadas con Las Prácticas Curricular Supervisadas, Trabajo de Carrera y Actividades Complementares.
} 
El Eje de Formación Práctica tiene como objetivo proporcionar al discente la integración entre la práctica y los contenidos teóricos desarrollados en los demás Ejes, aportándole vivencia en el medio de actuación del Derecho y autoconfianza para enfrentar situaciones en concreto, realizándola a través de los siguientes componentes curriculares: [...]" (Proyecto Pedagógico de la Carrera de Derecho de la FURG, 2006, p. 22.31 .

\section{Currículo de integración y educación emancipadora}

Al discutir los modos de gestión democrática, el currículo y las prácticas pedagógicas en escuelas públicas, Leite e Hypolito ${ }^{30}$, señalan:

Bernstein (2000) considera la Educación como una institución pública, basilar para la producción y reproducción de las injusticias distributivas. Argumenta que aspectos relacionados a la forma, a los contenidos, al acceso y a las oportunidades de la educación traen consecuencias, $\mathrm{y}$, entre otros aspectos, pueden enfatizar o comprometer posibilidades de afirmación, motivación e imaginación.

De esta forma, la educación emancipadora, y la integración curricular, no se opera de manera simple y rápida, pues para su conformación hay necesidad de contraponerse al modelo hegemónico un modelo contra-hegemónico, o emergente, pues como bien señala Henry Giroux ${ }^{31}$ (2005, p. 03):

Los ciudadanos de una democracia global deben de estar conscientes de la naturaleza interactiva de todos los aspectos de la vida cultural, espiritual y física. Lo que significa tener un entendimiento profundo de la naturaleza relacional de las dependencias globales, quiera hablemos de la ecosfera o de los circuitos del capital. En segundo lugar, los ciudadanos deben tener una cultura multifacética, de modo que no sólo les dé acceso a las nuevas tecnologías de la información y de las media, pero también les permita ser transgresores de fronteras preparados para empeñarse, aprender, interpretar y ser tolerantes y responsables relativamente a todo lo que involucre diferencia y alteridad. Lo que sugiere que se reclame los valores de validación mutua, de la dignidad y de la responsabilidad ética, como centrales a cualquier noción viable de ciudadanía.

Esta ruptura contra-hegemónica se da por la mirada de la teoría crítica de la educación, de la enseñanza jurídica y de la propia ruptura con la concepción liberal de ciudadanía $^{32}$, pues como bien nos hace memoria Ghedin ${ }^{33}$ :

\footnotetext{
${ }^{30}$ LEITE, Maria Cecilia Lorea e HYPOLITO, Álvaro Moreira. Modos de gestão, currículo e práticas pedagógicas. Disponible en web: http://www.anpae.org.br/iberolusobrasileiro2010/cdrom/71.pdf [consultado el 10 de octubre de 2010].

${ }^{31}$ GIROUX, Henry A. "Qual o papel da Pedagogia Crítica nos estudos de língua e cultura? Uma entrevista om Henry A. Giroux". En: Revista Language and Intercultural Communication. 2005, núm 6. Trad. Manuela Guilherme. Disponible en web: http://www.henryagiroux.com/RoleOfCritPedagogy_Port.htm [consultado el 12 de junio de 2010]

${ }^{32}$ Ver: MÉSZÁROS, István. A educação para além do capital. $2^{a}$ ed. Sao Paulo: Boitempo Editorial, 2008.
} 
La teoría crítica no es una simple perspectiva externa sobre los procesos de transformación [...] sino que integra el proceso de transformación, ayudando a los grupos a interpretarse en las formas de dominación a que se encuentran sometidos y a vislumbrar las posibilidades que se abren a ellos.

Al referirse a la posibilidad de transformación la Teoría Crítica ${ }^{34}$ avanza en el campo de la acción, y es por la educación que se produce este avance. Adorno ${ }^{35}$ afirma que:

[...] la educación sería impotente e ideológica si se ignorase el objetivo de adaptación y no preparase los hombres para orientarse en el mundo", por esta razón, según Adorno, nada mejor que una "educación para la emancipación.

De esta forma, este autor auxilia en el entendimiento que el locus educativo actúa como espacio propicio a la promoción de la ciudadanía; aquella sólidamente fundada por una educación reflexiva y emancipadora, pues como señala Adorno ${ }^{36}$ "la idea de la emancipación [...] necesita insertarse en el pensamiento y también en la práctica educacional".

Notoriamente la educación ha sido considerada por estudiosos de varias corrientes del pensamiento como siendo apta a responder a las cuestiones puestas por la sociedad. No es diferente el entendimiento de Bernard Charlot ${ }^{37}$ :

Esa transformación debe ser acompañada por una formación de los educadores, ella misma profundamente transformada. Implica el respeto a los principios de organización democráticos: organización democrático-participativa del currículo, de la gestión de los establecimientos (con participación de los propios alumnos, de representantes de padres, de representantes de la comunidad); reuniones regulares entre educadores y desarrollo de prácticas pedagógicas en grupos e interdisciplinar.

Así, la formación del profesor y la capacidad de interlocución docente con el cotidiano escolar son temáticas que involucran el repensar de las prácticas pedagógicas con dimensiones superiores al de los muros escolares. En estos términos, hay que concordar con Giroux $^{38}$, que comprende el papel del educador y del educando en una relación de intercambio y de discurso, lo que posibilita la emancipación y la reflexión, puesto que:

Los educadores deben ser considerados como intelectuales públicos que establecen la conexión entre las ideas críticas, las tradiciones, las disciplinas y los valores de la esfera pública en su día a día. Pero, a la vez, los educadores deben asumir la responsabilidad de unir su trabajo a las cuestiones sociales más amplias interrogándose sobre qué significa capacitar a sus alumnos para escribir textos políticos, para ser perseverantes ante la

\footnotetext{
${ }^{33}$ GHEDIN, Evandro. Professor reflexivo: da alienação da técnica à autonomia da crítica. En: PIMENTA, Selma Garrido; GHEDIN, Evandro (Orgs.). Professor reflexivo no Brasil: gênese e crítica de um conceito. Sao Paulo: Cortez, 2002.P. 39.

${ }^{34}$ Ver: FREITAG, Bárbara. A teoria crítica ontem e hoje. $3^{\mathrm{a}}$ ed. Brasiliense, Sao Paulo: 1990; NOBRE, Marco (Org). Curso livre de teoria crítica. Campinas, SP: Papirus,. 2008; PUCCI, Bruno (Org.). Teoria crítica e educação. A questão da formação cultural na Escola de Frankfurt. Sao Carlos, SP.: Vozes-Editora da UFScar, Petrópolis, RJ - 1995.

${ }^{35}$ ADORNO, Theodor W. Educação e Emancipação. Sao Paulo: Paz e Terra, 2010. P. 143.

${ }^{36}$ Ibid.

${ }^{37}$ Ibíd.

${ }^{38}$ GIROUX, Henry A. Ibíd. p. 4.
} 
LA EDUCACIÓN JURÍDICA EN BRASIL: UNA LECTURA CRÍTICA DE LAS DIRECTRICES CURRICULARES NACIONALES BRASILEÑAS PARA EL DERECHO Y SUS FORMAS DE RECONTEXTUALIZACIÓN A PARTIR DE LAS TEORÍAS DE BASIL BERNSTEIN

derrota, para analizar los problemas sociales y para aprender a utilizar los instrumentos de la democracia y a marcar la diferencia como agente social.

Concurre para ello el entendimiento de la naturaleza de la enseñanza que, necesariamente, en cuanto actividad social tiene como compromiso asegurar que todos aprendan, a la medida que la educación contribuye para la humanización y, por lo tanto, para la reducción de las desigualdades sociales. Entonces, parece que el concepto de "ensinagem" 39 comporta en sí la superación de la falsa dicotomía, pues trae consigo esos compromisos éticos, políticos y sociales de la actividad docente para con los alumnos, la que se realiza en determinado espacio institucional y fuera de él, como se da en la educación no formal. Así, se puede afirmar que enseñar es un proyecto colectivo. Aunque cada profesor, en su clase, posee autonomía para desarrollar su disciplina, ésta es parte integrante de un camino formativo del alumno ${ }^{40}$.

De esta forma, para este artículo defino educación emancipadora como un proceso educativo transversal y crítico, formal y no formal, centrado en una visión transdisciplinar de Derecho y de las Ciencias Humanas y Sociales como fuente de conocimiento que objetiva, estimula y sensibiliza el educando-licenciado (individual y colectivamente) en su consciencia participativa, emancipadora y de pertenencia, con base en los principios de la dignidad de la persona humana y del respeto a las diferencias culturales ${ }^{41}$.

En este punto, concuerdo con Arendt ${ }^{42}$ para quien "la educación es el punto en el que decidimos si amamos el mundo lo bastante para que asumamos la responsabilidad por él y, con tal gesto, salvarlo de la ruina que sería inevitable no fuese la renovación y la llegada de los nuevos y de los jóvenes", señalando que, en Santos ${ }^{43}$, la Universidad es la institución que, en las sociedades contemporáneas, mejor puede asumir el papel de emprender y emancipar, cuyo éxito reside en la "capacidad de hacer las cosas diferentemente" y cuya tarea está unida a quien piensa el saber jurídico para más allá del paradigma positivo hermético, es decir, un saber crítico, interdisciplinar y transformador ${ }^{44}$.

\footnotetext{
39 Para el concepto de “ensinagem” ver: Pimenta, Selma Garrido; Léa das Graças Camargos Anastasiou. Docência no Ensino Superior - Volume I. Sao Paulo: Cortez, 2002. P. 203-204.

${ }^{40}$ PIMENTA, Selma Garrido y ANASTASIOU, Léa das Graças Camargos. Docência no Ensino Superior Volume I. Sao Paulo: Cortez. 2002.

41 TOURAINE, Alain. Igualdade e diversidade: o sujeito democrático. Bauru, SP: EDUSC, 1998; TOURAINE, Alain. Crítica da modernidade. $6^{\mathrm{a}}$ ed. Petrópolis: Vozes, 1999.

${ }^{42}$ ARENDT, Hannah. Entre o passado e o futuro. Sao Paulo: Perspectiva, 1972. P. 247.

${ }^{43}$ SANTOS, Boaventura de Souza. Pela mão de Alice. O social e o político na pós-modernidade. $10^{\mathrm{a}}$ ed. Sao Paulo: Cortez, 2005. P. 236.

${ }^{44}$ APPLE, Michael W. Interromper a direita: realizar trabalho educativo crítico numa época conservadora. Currículo sem fronteiras. 2002, núm. 1, vol. 2. P. 80-98. Disponible en web: http://www.curriculosemfronteiras.org/vol2iss1articles/appleconf.pdf [consultado el 14 de septiembre de 2010]
} 
Así, entiendo que la integración curricular de los ejes de formación práctica, profesional y fundamental en la enseñanza jurídica, puede promover la educación emancipadora, pues como bien sostiene Beane $^{45}$ (2003, p.94):

Lo que estamos aquí a abordar es una concepción de currículo que busca relaciones en todas las direcciones, y que debido a ese tipo de unión especial, se le da el nombre integración curricular. Subyacentes a esta idea de integración curricular hay dos propósitos importantes. Por un lado, ayudar los jóvenes a integrar sus propias experiencias; por otro lado, promover la integración social democrática entre los jóvenes.

Así, conceptúo, para este artículo, currículo de integración, de acuerdo con Bernstein y, además, Leite e Hypolito ${ }^{46}$ que: "define el currículo de integración, el que las fronteras entre las categorías discursivas del currículo (disciplinas, contenidos curriculares) son tenues, habiendo la presencia de una idea integradora".

Entiendo que una primera aproximación al concepto de currículo se hace a partir del principio según el que se establece una relación especial entre las unidades de tiempo y sus contenidos. Así, para que se comprenda el modo como en un sistema educacional dado el currículo está estructurado, hay que analizar la relación entre los diferentes contenidos, y puede el análisis incidir sobre el estatuto relativo de cada contenido y sobre la delimitación de los diferentes contenidos particulares ${ }^{47}$.

De esta manera, analizar el estatuto relativo de un contenido dado significa considerar no sólo el tiempo que se le dedica, sino también la importancia que se le atribuye (conforme su naturaleza obligatoria o facultativa) y la delimitación de los diferentes contenidos - perspectiva más importante - significa considerar la fuerza de la frontera entre los contenidos. Es decir, si mantienen entre si una relación abierta, con fronteras claramente diferenciadas, o una relación cerrada, con fronteras bien definidas, y, por lo tanto, perfectamente aislados unos de otros, sirven como referencial para comprender el currículo de modo integral.

Pienso que es posible afirmar que no hay nada de intrínseco en el modo como un dado currículo se estructura, independientemente de la lógica intrínseca a las varias formas de conocimiento, las formas da su transmisión son hechos sociales. Hay muchos medios alternativos de acceso al conocimiento y, por lo tanto, las varias realidades que esas formas hacen posible. De acuerdo con esta perspectiva, considero que cualquier currículo involucra principios según el que se establezca alguna normativa especial referida a sus contenidos, estableciéndose una relación abierta o cerrada entre ellos ${ }^{48}$.

Según Bernstein ${ }^{49}$, a partir de la forma de relación que los contenidos de estatuto más elevado mantienen entre sí, pueden definirse dos tipos fundamentales de currículo:

\footnotetext{
${ }^{45}$ BEANE, James A. Integração curricular: a essência de uma escola democrática. Currículo sem fronteiras. 2003, núm. 2, vol. 3. P. 91-110. Disponible en web: http://www.curriculosemfronteiras.org/vol3iss2articles/beane. pdf. [consultado el 12 de septiembre de 2010].

${ }^{46}$ LEITE, Maria Cecilia Lorea; HYPOLITO, Álvaro Moreira. Ibíd. P. 11.

${ }^{47}$ Ver en: BERNSTEIN, Basil. Pedagogía, Control Simbólico e Identidad. Madrid: Ediciones Morata, 2006.

${ }^{48}$ Ibíd.

${ }^{49}$ Ibíd.
} 
currículo de colección y currículo de integración. Si los contenidos mantienen entre sí una relación cerrada, se le denomina "currículo de colección". Si, por el contrario, no hay límites bien definidos, manteniendo los contenidos una relación abierta entre sí, se denomina "currículo de integración". En casos extremos, se podría decir que en un currículo de colección todos los períodos de tiempo serían marcadamente fijos y ninguno de los contenidos sería abierto y que en un currículo de integración no habría períodos fijos de tiempo y todos los contenidos serían abiertos. En realidad, lo que se comprueba son diferentes formas de colección y varios grados de integración.

De esta forma, cualquier currículo de colección está organizado acerca de materias que se mantienen en una relación cerrada y que involucran una jerarquía en la que el "tesoro perdido" se revela muy tardíamente en la vida educacional, viendo entonces el proceso formativo a través de la forma de una "larga jornada en la búsqueda de un tesoro perdido". En otras palabras, el conocimiento no se encara como sentido común, sino como algo "intocable", al cual no todos tienen acceso y, es más, como se representa como "tesoro perdido", que solo se desvela al final del largo camino, que es la educación. Este es el hecho que engrandece el significado de las relaciones en el salón de clase y de los que abogan por una educación sacralizada. Siendo sagrado, el conocimiento surge todavía como si fuese propiedad privada, con varios tipos de fronteras simbólicas, así visto las personas que poseen ese conocimiento aparecen como poseedoras de un monopolio.

En un currículo de colección, el conocimiento está organizado en contenidos aislados, cada profesor en su campo puede, dentro de ciertos límites prescritos, seguir un camino propio. En ese currículo, la pedagogía es didáctica y los criterios de evaluación independientes. Las rubricas programáticas de cada contenido están en manos de quien enseña y de quien evalúa lo que va a permitir la existencia de diferencias considerables, quiera en la práctica de enseñanza, quiera en las formas de evaluación ${ }^{50}$.

Según Bernstein ${ }^{51}$, en un currículo de integración los distintos contenidos están subordinados a una idea central que, reduciendo el aislamiento entre ellos, los agrega en un todo más amplio. Cada contenido deja de tener significado por si sólo para asumir una importancia relativa y pasa a tener una función bien determinada y explícita dentro del todo del que hace parte.

Una vez que en un currículo de integración el conocimiento está organizado en contenidos abiertos que se entrecruzan en torno a una idea central, integradora, los diferentes profesores están involucrados en una tarea compartida, lo que conduce a la necesidad de una pedagogía y de un estilo de examen comunes. No obstante, más allá de tener que haber una práctica pedagógica común, ésta debe centrarse en el modo de cómo se adquiere el conocimiento y no en los estados del conocimiento.

Por último, pero sin finalizar, es necesario precisar que en un currículo de colección, la teoría pedagógica subyacente es la didáctica; y, al contrario, en un currículo de integración, esa teoría tiende a ser de (auto)regulación. Con la colección, los criterios de evaluación son diferentes y definidos independientemente por cada profesor; con la integración, esos criterios son comunes. Un currículo de colección, sobre todo en su forma

\footnotetext{
${ }^{50}$ Ibid.

${ }^{51}$ Ibíd.
} 
especializada, promueve una enseñanza en profundidad; un currículo de integración conduce a una enseñanza que se extiende ${ }^{52}$.

\section{Consideraciones finales}

Sostengo que las carreras de Derecho (incluso la que he analizado) tienen por base una organización curricular con una fuerte separación y clasificación -curriculum de colección ${ }^{53}$-, pero eso no impide que se implemente la integración -currículo de integración- del eje de formación práctica, con una clasificación débil, ya que como bien señalan Leite e Hypolito ${ }^{54}$, al referirse a James Beane,:

El currículo integrado, elaborado en torno a problemas y cuestiones significativas identificadas tanto por los docentes como por los discentes, contemplando posibilidades de integración personal y social e incentivando el trabajo colaborativo, la participación en la propia selección de los contenidos estudiados, de forma a debilitar fronteras de categorías anteriormente fuertemente clasificadas, tiende a resultar, según su experiencia de investigación, en mejores desempeños de los alumnos y en prácticas más democráticas en la Escuela.

Sin embargo, hay que tener en cuenta que escoger la integración curricular necesita tener como foco la búsqueda de una educación emancipadora.

Espero haber dejado claro que el discurso de la integración curricular es mucho más matizado de lo que a la primera vista puede parecer. No se trata de un bien en sí, de carácter meramente instrumental, tampoco debe ser consensual su defensa. Todo lo contrario, exige la comprensión de que principios integradores se están considerando y a que finalidades educacionales la integración curricular se está sometiendo. Pura y simplemente defender un currículo integrado no remite el discurso o el interlocutor a una perspectiva emancipadora. ${ }^{55}$

De modo que, solamente así, esta perspectiva de integración curricular del eje de la formación práctica, con los demás ejes de la carrera de Derecho -fundamental y profesional-, pueden contribuir para la generación y sustentación de una educación emancipadora, crítica y de ciudadanía activa.

\footnotetext{
${ }^{52}$ Ibíd.

${ }^{53}$ BERNSTEIN, Basil. Poder, Educación y Conciencia. Sociología de La Transmisión cultural. Barcelona: El Roure Editorial, 1990.

${ }^{54}$ LEITE, Maria Cecilia Lorea; HYPOLITO, Álvaro Moreira. Ibíd. P. 12.

${ }^{55}$ LOPES, Alice Casemiro e MACEDO, Elizabeth (Orgs.). Disciplinas e integração curricular: história e políticas. DP\&A, Río de Janeiro. 2002. p. 171.
} 


\section{Referencias bibliográficas}

ADORNO, Theodor W. y HORKHEIMER, Max. Dialética do esclarecimento. Río de Janeiro: Jorge Zahar Editor, 1969.

ADORNO, Theodor W. Educação e Emancipação. Sao Paulo: Paz e Terra, 2010.

ALEXY, Robert. Teoria dos direitos fundamentais. Trad. Virgílio Afonso da Silva. Sao Paulo: Malheiros, 2008.

Anuário ABEDI (Associação Brasileira de Ensino do Direito). 2004, año 2, núm. 2.

Anuário ABEDI (Associação Brasileira de Ensino do Direito). 2005, año 3, núm. 3.

APPLE, Michael W. "Interromper a direita: realizar trabalho educativo crítico numa época conservadora. Currículo sem fronteiras". 2002, vol. 2. núm. 1. P. 80-98. Disponible en web: http://www.curriculosemfronteiras.org/vol2iss1articles/appleconf.pdf [consultado el 14 de septiembre de 2010].

ARENDT, Hannah. Entre o passado e o futuro. Sao Paulo: Perspectiva, 1972.

ARENDT, Hannah. A condição humana. Sao Paulo: Forense Universitária, 1999.

BEANE, James A. "Integração curricular: a essência de uma escola democrática. Currículo sem fronteiras". 2003, vol. 3, núm. 2. P. 91-110. Disponible en web: http://www.curriculosemfronteiras.org/vol3iss2articles/beane.pdf [consultado el 12 de septiembre de 2010].

BERNSTEIN, Basil. Poder, Educación y Conciencia. Sociología de La Transmisión cultural. Barcelona: El Roure Editorial, 1990.

BERNSTEIN, Basil. A estruturação do discurso pedagógico: classe, códigos e controle. Petrópolis: Vozes, 1996.

BERNSTEIN, Basil. Pedagogía, Control Simbólico e Identidad. Madrid: Ediciones Morata, 1996.

BITTAR, Eduardo C. B. "O ensino jurídico na pós-modernidade”. En: Anuário ABEDI (Associação Brasileira de Ensino do Direito). 2005, año 3, núm. 3.

BRASIL. Constituição da República Federativa do Brasil. Sao Paulo: Saraiva, 2009.

BRASIL. Portaria Ministerial $\mathrm{n}^{\circ}$ 1886. Fixa as diretrizes curriculares e o conteúdo mínimo do curso jurídico. 30 de diciembre de 1994. Disponible en web: http://www.oab.org.br/arquivos/pdf/LegislacaoOab/LegislacaosobreEnsinoJuridico.pdf [consultado el 12 de septiembre de 2010].

BRASIL. Resolução do Conselho Nacional de Educação - Câmara de Educação Superior n 09. Institui as diretrizes curriculares nacionais do Curso de Graduação em Direito e dá outras providências. 27 de setembro de 2004. Disponible en web: http://portal.mec.gov.br/cne/arquivos/pdf/rces09_04.pdf [consultado el 11 de octubre de 2010].

CHARLOT, Bernard. Texto presentado en el II Foro Social Mundial por el Foro Mundial de Educación. Porto $\quad$ Alegre, $2003 . \quad$ Disponible en http://paje.fe.usp.br/ mbarbosa/cursograd/charlot.doc [consultado el 12 de Julio de 2010]

COSTA, Marisa Vorraber (Org.). O currículo nos limiares do contemporâneo. $3^{\mathrm{a}}$ ed. Río de Janeiro: DP\&A, 2003. 
DAHL, Robert. Sobre a democracia. Brasilia: UnB, 2001.

FERRAZ Jr., Tércio Sampaio. A ciência do direito. $2^{\text {a }}$ ed. Sao Paulo: Atlas, 1980.

FRAGALE FILHO, Roberto. "Diretrizes curriculares". En: Anuário ABEDI (Associação Brasileira de Ensino do Direito). 2004, año 2, núm. 2.

FREITAG, Bárbara. A teoria crítica ontem e hoje. $3^{\text {a }}$ ed. Sao Paulo: Brasiliense, 1990.

GHEDIN, Evandro. "Professor reflexivo: da alienação da técnica à autonomia da crítica". En. PIMENTA, Selma Garrido y GHEDIN, Evandro (Orgs.). Professor reflexivo no Brasil: gênese e crítica de um conceito. Sao Paulo: Cortez, 2002.

GHIGGI, Gomercindo y VAN-DÚNEM, José Octávio S. (Orgs.). Diálogos educativos entre Brasil e Angola. Pelotas: Editora e Gráfica Universitária, UFPel, 2007.

GIROUX, Henry A. "Qual o papel da Pedagogia Crítica nos estudos de língua e cultura? Uma entrevista om Henry A. Giroux". En: Revista Language and Intercultural Communication. 2005, núm 6. Trad. Manuela Guilherme. Disponible en web:

http://www.henryagiroux.com/RoleOfCritPedagogy_Port.htm [consultado el 12 de junio de 2010]

HARVEY, David. Condição pós-moderna. 6ª ed. Sao Paulo: Edições Loyola, 2002.

HENNING, Ana Clara Correa. "Conexões entre cultura popular e cultura acadêmica: recontextualização curricular na prática de pesquisa jurídica do curso de direito da Anhanguera Educacional/Faculdade Atlântico Sul em Pelotas". Dissertação de Mestrado, Programa de PósGraduação em Educação, Faculdade de Educação. Pelotas, RS, UFPel, 2008.

HYPOLITO, Álvaro Moreira. "Políticas educacionais e políticas de gestão no Brasil". In: GHIGGI, Gomercindo y VAN-DÚNEM, José Octávio S. (Orgs.). Diálogos educativos entre Brasil e Angola. Pelotas, RS: Editora e Gráfica Universitária, UFPel, 2007.

LEITE, Maria Cecilia Lorea. Decisões pedagógicas e inovações no ensino jurídico. v. I. Tesis de Doctorado. Programa de Postítulo en Educación. Porto Alegre: UFRGS, 2003

LEITE, Maria Cecilia Lorea e VAN-DÚNEM, José Octávio S. “Avaliação do curso de direito e inovações: desafios da pedagogia jurídica". En: GHIGGI, Gomercindo e VAN-DÚNEM, José Octávio S. (Orgs.). Diálogos educativos entre Brasil e Angola. Pelotas, RS: Editora e Gráfica Universitária, UFPel, 2007.

LEITE, Maria Cecilia Lorea y HYPOLITO, Álvaro Moreira. Modos de gestão, currículo e práticas pedagógicas. Disponible en web: http://www.anpae.org.br/iberolusobrasileiro2010/cdrom/71.pdf [consultado el 10 de octubre de 2010].

LOPES, Alice Casemiro y MACEDO, Elizabeth (Orgs.). Disciplinas e integração curricular: história e políticas. Río de Janeiro: DP\&A, 2002.

LOPES, Alice Ribeiro Casemiro; MACEDO, Elizabeth Fernandes de y ALVES, Maria Palmira Carlos (Orgs.) Cultura e política de currículo. Araraquara, SP: Junqueira \& Marin Editores, 2006.

MACEDO, Magda Helena Soares. Manual de metodologia da pesquisa jurídica. $2^{\mathrm{a}}$ ed. Porto Alegre: Editora Sagra Luzzatto, 2001.

MARSHALL, T. H. Cidadania, classe social e status. Río de Janeiro: Zahar Editores, 1967.

MÉSZÁROS, István. A educação para além do capital. $2^{\mathrm{a}}$ ed. Sao Paulo: Boitempo Editorial, 2008. 
LA EDUCACIÓN JURÍDICA EN BRASIL: UNA LECTURA CRÍTICA DE LAS DIRECTRICES CURRICULARES NACIONALES

BRASILEÑAS PARA EL DERECHO Y SUS FORMAS DE RECONTEXTUALIZACIÓN A PARTIR DE LAS TEORÍAS DE BASIL BERNSTEIN

MOREIRA, Antonio Flávio e SILVA, Tomaz Tadeu da. (Orgs.). Currículo, cultura e sociedade. 11 ed. Sao Paulo: Cortez Editora, 2009.

NALINI, José Renato e CARLINI, Angélica (Coord.) Direitos humanos e formação jurídica. Río de Janeiro: Forense, 2010.

NOBRE, Marco (Org). Curso livre de teoria crítica. Campinas, SP: Papirus, 2008.

NUNES, Edson; NOGUEIRA, André Magalhães y RIBEIRO, Leandro Molhano. Futuros possíveis, passados indesejáveis: selo da OAB, provão e avaliação superior. Río de Janeiro: Garamond, 2001.

OLIVEIRA, Olga Maria Boschi Aguiar de. Monografia Jurídica: orientações metodológicas para o trabalho de conclusão de curso. $3^{\mathrm{a}}$ ed. Porto Alegre: Síntese, 2003.

PEREIRA, Júlio Emílio Diniz. Formação de professores: pesquisas, representação e poder. Belo Horizonte: Autêntica, 2000.

PUCCI, Bruno (Org.). Teoria crítica e educação. A questão da formação cultural na Escola de Frankfurt. Petrópolis, RJ - Sao Carlos, SP: Vozes - Editora da UFScar, 1995.

PIMENTA, Selma Garrido y ANASTASIOU, Léa das Graças Camargos. Docência no Ensino Superior - Vol. I. Sao Paulo: Cortez, 2002.

RODRIGUES, Horácio Wanderlei y JUNQUEIRA, Eliane Botelho. Ensino do Direito do Brasil. Florianópolis: Fundação Boiteux, 2002.

RODRIGUES, Horácio Wanderlei. Pensando o Ensino do Direito no Século XXI. Florianópolis: Fundação Boiteux, 2005.

SANTOS, André Leonardo Copetti y MORAIS, José Luis Bolzan de. O ensino jurídico e a formação do bacharel em Direito - Diretrizes político-pedagógicas do curso de direito da UNISINOS. Porto Alegre: Livraria do Advogado, 2007.

SANTOS, Boaventura de Souza. O discurso e o poder. Porto Alegre: Fabris, 1988.

SANTOS, Boaventura de Souza. A critica da razão indolente: contra o desperdício da experiência. Para um novo senso comum. A ciência, o direito e a política na transição paradigmática. Vol. 1. Sao Paulo: Cortez Editora, 2000.

SANTOS, Boaventura de Souza (Org). Reconhecer para libertar: os caminhos do cosmopolitismo multicultural. Río de Janeiro: Civilização Brasileira, 2003.

SANTOS, Boaventura de Souza. Pela mão de Alice. O social e o político na pósmodernidade. $10^{\mathrm{a}}$ ed. Sao Paulo: Cortez, 2005.

SANTOS, Boaventura de Souza. Renovar a teoria crítica e reinventar a emancipação social. Sao Paulo: Boitempo Editorial, 2007.

SILVA, Tomaz Tadeu da y MOREIRA, Antonio Flávio. (Orgs.). Territórios contestados: o currículo e os novos mapas políticos e culturais. $4^{\mathrm{a}}$ ed. Petrópolis, RJ: Vozes, 2001.

SILVA, Tomaz Tadeu da. O currículo como fetiche - a poética e a política do texto curricular. Belo Horizonte: Autêntica, 2003.

SILVA, Tomaz Tadeu da. Documentos de identidade. $2^{\mathrm{a}}$ ed. Belo Horizonte: Autêntica, 2005.

TOURAINE, Alain. Igualdade e diversidade: o sujeito democrático. Bauru, SP: EDUSC, 1998.

TOURAINE, Alain. Crítica da modernidade. $6^{\text {a }}$ ed. Petrópolis, RJ: Vozes, 1999. 
UNIVERSIDADE FEDERAL DO RIO GRANDE. Curso de Direito. Projeto Político Pedagógico. Río Grande: FURG, 2007.

UNIVERSIDADE FEDERAL DO RIO GRANDE. Curso de Direito. Regulamento da Prática e do Estágio Supervisionado. Río Grande: FURG, 2010.

UNIVERSIDADE FEDERAL DO RIO GRANDE. Curso de Direito. Matriz Curricular. Río Grande: 2007 y 2010.

VALLE, Leila Mara Barbosa Costa. O curso de direito na FURG. En: Revista Júris. 2005, núm. 11. Pp. 33-45. 